\title{
Relationships Among Wilt-Inducing Isolates of Fusarium oxysporum from Sweetpotato and Tobacco
}

\author{
C. A. Clark, J-W. Hyun, and M. W. Hoy, Department of Plant Pathology and Crop Physiology, Louisiana Agri-
} cultural Experiment Station, Louisiana State University Agricultural Center, Baton Rouge 70803-1720

\begin{abstract}
Clark, C. A., Hyun, J-W., and Hoy, M. W. 1998. Relationships among wilt-inducing isolates of Fusarium oxysporum from sweetpotato and tobacco. Plant Dis. 82:530-536.

Thirty-five isolates of Fusarium oxysporum obtained from diseased sweetpotato or tobacco were compared for pathogenicity on two cultivars each of sweetpotato and tobacco, by random amplified polymorphic DNA (RAPD) profiles, and by vegetative compatibility group (VCG) analysis. Analysis of RAPD profiles revealed five clusters of isolates that corresponded to patterns of pathogenicity. One cluster of isolates, designated as $F$. oxysporum f. sp. nicotianae, induced severe wilting on both tobacco cultivars but varied from weakly to highly aggressive on the sweetpotato cultivars. Four of the 16 isolates from this group were originally isolated from sweetpotato, and 1 isolate caused severe disease on both crops. Three clusters included isolates from sweetpotato that were virulent on Porto Rico, caused little or no disease on Beauregard and burley tobacco (cv. Kentucky 5), and did not cause wilt on flue-cured tobacco (cv. Gold Dollar). These isolates were designated as race 0 of $F$. oxysporum $\mathrm{f}$. sp. batatas. Isolates obtained from sweetpotato from California clustered separately from other sweetpotato isolates and the tobacco isolates. They differed from other sweetpotato isolates in being virulent on Beauregard and are proposed as a new race 1 of $F$. oxysporum $\mathrm{f}$. sp. batatas. VCG analysis was of limited value with the isolates in this study because many isolates were self-incompatible. In each case, all members of a VCG fell within the same cluster defined by RAPDs. This study demonstrated that $F$. oxysporum from at least three genetically distinct lineages can cause Fusarium wilt on sweetpotato, and that the host ranges of $F$. oxysporum f. sp. batatas and $F$. oxysporum f. sp. nicotianae overlap and include plants from two different families.
\end{abstract}

Fusarium wilt or stem rot of sweetpotato (Ipomoea batatas), a disease that once was a limiting factor to sweetpotato production in the United States, is caused by Fusarium oxysporum f. sp. batatas (8). Sweetpotato yields in the southeastern United States remained consistently poor prior to the 1950s (5), when resistance to Fusarium wilt was introduced and yields began to steadily increase $(5,7,8)$. Sweetpotato cultivars released in the United States over the past few decades have resistance to this disease (7). In addition, chlorotic leaf distortion (CLD), caused by F. lateritium, has become widespread and cross-protects sweetpotato against Fusarium wilt (6). Because of this natural cross-protection and widespread use of resistance, Fusarium wilt is now rarely encountered in the

Corresponding author: C. A. Clark

E-mail: xp1484@unix1.sncc.lsu.edu

Financial support provided by the Louisiana Sweet Potato Advertising and Development Commission, the Louisiana Agricultural Experiment Station, and the Korea Science and Engineering Foundation. Approved for publication by the Director of the Louisiana Agricultural Experiment Station as manuscript 97-38-0296.

Accepted for publication 2 February 1998.

Publication no. D-1998-0306-02R

(C) 1998 The American Phytopathological Society southeastern United States (7). Beauregard, the predominant sweetpotato cultivar in production in the United States at present, is resistant to isolates from sweetpotato in the southeast $(15,16,24)$. However, during the early $1990 \mathrm{~s}$, there were anecdotal reports of a stem rot occurring on Beauregard in California (R. Scheuerman, personal communication). In isolations from affected vines sent from one source in California, we isolated both $F$. oxysporum and Erwinia chrysanthemi from each plant (Clark, unpublished data). In addition, isolates of $F$. oxysporum obtained in California from the wilt-susceptible cultivar Golden Sweet caused moderate levels of wilt in artificial inoculations of wilt-resistant Jewel and Beauregard plants (R. N. Campbell, personal communication). Thus, one objective of this research was to compare isolates of $F$. oxysporum from California with isolates of $F$. oxysporum from the southeastern United States to determine if they represent races of the pathogen.

It had been suggested by several workers that strains of $F$. oxysporum that cause wilt on sweetpotato, cotton (Gossypium hirsutum), and tobacco (Nicotiana tabacum) share a common host, burley tobacco $(1,26)$. Isolates of the pathogen from all three hosts cause disease in burley tobacco. Based on extensive inoculation studies, Smith and Shaw described three "races" of $F$. oxysporum based on differential reac- tions on the three different crop species (26). Armstrong and Armstrong amended this to two races each of $F$. oxysporum $\mathrm{f}$. sp. batatas and $F$. oxysporum f. sp. vasinfectum (1). Race 1 of $F$. oxysporum $\mathrm{f}$. sp. batatas caused wilt only on sweetpotato and burley tobacco; race 2 also caused wilt on flue-cured tobacco. Likewise, race 1 of F. oxysporum f. sp. vasinfectum caused wilt of cotton and burley tobacco, and race 2 also induced wilt in flue-cured tobacco. The cotton and sweetpotato races caused wilt only on their respective hosts.

Fusarium wilt of tobacco has been attributed by some authors to $F$. oxysporum $\mathrm{f}$. sp. nicotianae $(18,25)$ and by other authors to F. oxysporum f. sp. batatas (19). However, Armstrong and Armstrong excluded $F$. oxysporum f. sp. nicotianae from their list of forma speciales because they could not find evidence in the literature of a forma specialis of $F$. oxysporum that was specific to tobacco (3). Instead, they included the former $F$. oxysporum f. sp. nicotianae isolates in $F$. oxysporum $\mathrm{f}$. $\mathrm{sp}$. batatas, such that this forma specialis included strains pathogenic to both sweetpotato and tobacco. La Mondia compared isolates from shade and broadleaf tobacco in Connecticut by pathogenicity and vegetative compatibility grouping (19). He grouped these isolates into two vegetative compatibility groups (VCGs) and also included in VCG 1 isolates from burley tobacco from Kentucky, flue-cured tobacco from North Carolina, and two isolates from sweetpotato. All of the pathogenic isolates caused wilt in broadleaf and burley tobacco but not in fluecured tobacco. Otherwise, there have been no comprehensive comparisons of wilt-inducing strains of $F$. oxysporum from tobacco with those from other hosts, and the relationship between pathogens from the two host species has been confusing.

In this study, we compared isolates of $F$. oxysporum from sweetpotato and tobacco from several locations within the United States for pathogenicity on a susceptible and resistant cultivar of sweetpotato and on the cultivars of burley and flue-cured tobacco that were used to define races by Armstrong and Armstrong. These results were compared to VCGs and random amplified polymorphic DNA (RAPD) patterns obtained from the isolates.

\section{MATERIALS AND METHODS}

Isolates. Isolates were obtained from various sources (Table 1). Each isolate was 
prepared from a single spore transfer by the original isolator. Isolates were preserved on silica gel crystals (27) and stored at $-20^{\circ} \mathrm{C}$.

Pathogenicity tests. In initial tests, cultures were grown in $75 \mathrm{ml}$ Czapek's broth in 500-ml Erlenmeyer flasks at room temperature (approx. $24^{\circ} \mathrm{C}$ ) on a shaker at $200 \mathrm{rpm}$ for 5 to 7 days. The cultures then were filtered through 4 layers of sterile cheesecloth. Since some isolates did not produce sufficient inoculum under these conditions, in subsequent tests cultures were grown on 9-cm-diameter petri dishes of potato dextrose agar (PDA) under a combination of fluorescent (Sylvania F40/CW) and black (Philips F40 BLB) lights for 5 to 7 days. Cultures then were rinsed with sterile distilled water and the resulting suspensions were filtered through 4 layers of sterile cheesecloth. Suspensions were diluted with sterile distilled water to a concentration of $1.0 \times 10^{6}$ propagules $/ \mathrm{ml}$ based on counts made with a hemacytometer, unless otherwise indicated.

To avoid confounding results from natural cross-protection by $F$. lateritium, inoculations of sweetpotato were performed only on plants that had been derived from meristem-tip culture and that were free of CLD symptoms (6). Terminal vine cuttings 20 to $30 \mathrm{~cm}$ long of the cultivars Porto Rico (wilt-susceptible) and Beauregard (wilt-resistant) were stripped of all expanded leaves by breaking the petiole from the stem. The vine cuttings were placed in a plastic bag, the appropriate inoculum was added, and the bag was gently manipulated to assure uniform distribution of the inoculum over the plants. The cuttings were then planted in $15-\mathrm{cm}$-diameter clay pots filled with a standard soil mix of 1:1:1 (vol) autoclaved river silt, autoclaved sand, and Jiffy Mix (Jiffy Products of America, West Chicago, IL). Four or five cuttings were planted in each pot and three or four replicate pots were arranged in a randomized complete block design (RCBD) on a bench in a greenhouse. The pots were misted for the first 3 to 4 days ( 8 sec every $10 \mathrm{~min}, 600$ to $2000 \mathrm{~h}$ ) and then watered as needed thereafter. Tests were conducted from April through October when there was a minimum of $12 \mathrm{~h}$ daylight and greenhouse temperatures ranged between nighttime lows of 21 to $26^{\circ} \mathrm{C}$ and daytime highs of 32 to $38^{\circ} \mathrm{C}$. Because of the limited supply of CLD-free cuttings, inoculations were done in batches and each isolate was included in at least two tests. Isolate CB-3 from sweetpotato was included as a standard in batches when possible, because it caused intermediate levels of disease on both sweetpotato cultivars.

In addition to pathogenicity tests as above, a representative isolate (CB-3) from the California sweetpotato group and a sweetpotato isolate (WJM-7) from Louisiana were compared on Porto Rico and Beauregard over a range of five inoculum densities between $1.0 \times 10^{4}$ and $1.0 \times 10^{6}$ propagules $/ \mathrm{ml}$. Inoculations were conducted as above and the experiment was conducted four times.

Tobacco seed of the burley cultivar Kentucky 5 and the flue-cured cultivar Gold Dollar were planted in flats of Jiffy Mix, and plants were grown until they were approximately 5 to $7 \mathrm{~cm}$ tall. Plants were lifted and the roots were placed in 9$\mathrm{cm}$-diameter sterile plastic petri dishes to which the appropriate inoculum was added. Inoculated seedlings were planted three plants per pot in standard soil mix in 10cm-diameter clay pots and placed in a RCBD in a greenhouse under the same misting conditions as above. All isolates were compared in at least two tests.

Two methods were used in two tests to assess pathogenicity of isolates on cotton cultivar Stoneville 825 (Fusarium wiltsusceptible). In the first test, seeds were planted in 10-cm-diameter pots in standard soil mix and thinned to give three seedlings per pot. After 1 week, roots were injured by running a flamed knife through the soil and the soil was then infested with $5 \mathrm{ml}$ inoculum. Since no wilt developed after the first inoculation, the same plants were reinjured and reinoculated at 5 weeks after planting with about $30 \mathrm{ml}$ inoculum per pot. The second method consisted of germinating cotton seed in soil mix, lifting the seedlings 10 days after planting, dipping the seedlings in inoculum, and replanting the seedlings in separate $2-$ by $2-\mathrm{cm}$ cells in compartmentalized polystyrene planting trays. These were placed under mist conditions as above for 3 days and then watered as needed.

After 2 weeks for sweetpotato, and 3 weeks for cotton and tobacco, disease ratings were made. The stem of each plant was cut on a diagonal at about 1 to $2 \mathrm{~cm}$ above the soil and the plants were rated using the following scale: $0=$ no symptoms, $1=$ slight vascular discoloration with no external symptoms, $2=$ moderate vascular discoloration with no external symptoms, 3 = lower leaves yellowed and incipient wilting, $4=$ extensive wilting, and $5=$ plant dead.

SAS (version 6.04 for PC, SAS Institute, Cary, NC) was used for statistical analysis. Wilt indices on the tobacco cultivars were analyzed by the analysis of variance (ANOVA) procedure and least significant difference (LSD; $\alpha=0.05$ ) was determined. In addition, standard deviation of the mean was calculated for each isolate for all tests in which it was included. Since it was not possible to inoculate the sweetpotato cultivars with all isolates at the same time, isolate CB-3 was included as a standard in tests because it usually induced intermediate levels of disease on both cultivars. In a few tests, CB-3 did not induce wilting in Porto Rico; these tests were excluded. Standard deviation of the mean was calculated for each isolate for all tests in which it was included. ANOVA and regression analyses were used to analyze mean wilt indices in inoculum density tests with isolates CB-3 and WJM-7 on Porto Rico and Beauregard sweetpotato.

Random amplified polymorphic DNA analysis. Each isolate was grown in stationary culture in 2 100-ml flasks containing $50 \mathrm{ml}$ potato dextrose broth for 7 to 10 days at room temperature (approx. $24^{\circ} \mathrm{C}$ ). DNA was extracted by the method of Yoon (28). Approximately $100 \mathrm{mg}$ fresh weight mycelium was triturated with a precooled mortar and pestle and mixed with $1 \mathrm{ml}$ lysis buffer (50 mM Tris- $\mathrm{HCl}[\mathrm{pH} 7.2], 50$ mM EDTA [pH 7.2], 3\% sodium dodecyl sulfate, and 1\% 2-mercaptoethanol). This was incubated in a 2-ml microcentrifuge tube at $65^{\circ} \mathrm{C}$ for $1 \mathrm{~h}$ with occasional agitation. One volume of chloroform:isoamyl alcohol (24:1, vol:vol) was added and the mixture was centrifuged at $11,750 \times g$ for $10 \mathrm{~min}$ at room temperature. The upper phase was transferred to a new $1.5-\mathrm{ml} \mathrm{mi-}$ crocentrifuge tube, 0.1 vol. $3 \mathrm{M}$ sodium acetate and 1 vol. isopropanol were added and mixed, then centrifuged at 11,750 $\times g$ for $5 \mathrm{~min}$ at room temperature. The pellet was rinsed with cold $70 \% \mathrm{EtOH}$, dried, and resuspended in $0.1 \mathrm{ml}$ TE $(10 \mathrm{mM}$ Tris- $\mathrm{HCl}, 1 \mathrm{mM}$ EDTA, $\mathrm{pH} 8.0$ ), and $0.1 \mathrm{~g}$ $\mathrm{CsCl}$ was added and dissolved. This was centrifuged at $11,750 \times g$ for $10 \mathrm{~min}$, the supernatant was transferred to a new tube, and 2 vols of TE were added. Two vols of EtOH were added, the mix was incubated at $-20^{\circ} \mathrm{C}$ for $15 \mathrm{~min}$, and the DNA was pelleted by centrifugation at $11,750 \times g$ for $5 \mathrm{~min}$ at room temperature. The pellet was rinsed twice with cold $70 \% \mathrm{EtOH}$, dried, and resuspended in $200 \mu \mathrm{l}$ TE. DNA concentration was determined with a TKO 100 fluorometer (Hoefer Scientific Instruments, San Francisco, CA) using Hoechst 33258 dye (Molecular Probes, Inc., Eugene, OR). DNA was stored at $4^{\circ} \mathrm{C}$.

Ten-base oligonucleotide primers from Operon primer kit A (Operon Technologies, Inc., Alameda, CA) were used. Amplification reactions were done in $25-\mu 1$ reaction mixtures containing $5 \mu 110 \times \mathrm{Taq}$ DNA polymerase reaction buffer (Promega Corp., Madison, WI), $2.5 \mathrm{mM} \mathrm{MgCl}_{2}, 0.2$ $\mathrm{mM}$ each dATP, dCTP, dGTP, and dTTP, $0.2 \mu \mathrm{M}$ of the appropriate primer, approximately $5 \mathrm{ng}$ template DNA, and 1 unit Taq DNA polymerase (Promega Corp.). Each reaction was overlaid with 2 drops (approximately $25 \mu \mathrm{l}$ ) sterile mineral oil. Reactions were carried out in $0.5-\mathrm{ml}$, thin-walled polymerase chain reaction (PCR) tubes. Amplifications were performed in a programmable thermocycler (model 480, Perkin-Elmer Cetus, Norwalk, CT) with the following parameters: initial denaturation for $2 \mathrm{~min}$ at $95^{\circ} \mathrm{C}$ followed by 40 amplification cycles of denaturation at $94^{\circ} \mathrm{C}$ for $30 \mathrm{sec}$, annealing at $40^{\circ} \mathrm{C}$ for 1 min, extension at $72^{\circ} \mathrm{C}$ for $2 \mathrm{~min}$, followed by a final extension at $72^{\circ} \mathrm{C}$ for $10 \mathrm{~min}$. At 
least two independent amplifications were conducted for each isolate/primer combination. After PCR, $12 \mu 1$ product was electrophoresed in a $1.5 \%$ agarose gel in Trisacetate EDTA buffer for $2 \mathrm{~h}$ at $3 \mathrm{~V} / \mathrm{cm}$ and bands were visualized following staining with ethidium bromide on a UV transilluminator. A 1-kilobase (kb) DNA ladder (Gibco BRL, Gaithersburg, MD) was used as a molecular weight standard. Profiles for each primer were compared on the basis of presence or absence of RAPD products of the same electrophoretic mobility. Relative relatedness among isolates was assessed by multivariate analysis of similarity coefficients (SIMQUAL), and a matrix of similarity coefficients for each pair of isolates was constructed. A cluster analysis on the similarity coefficients was performed with the unweighted pair-group method algorithm (UPMGA) contained in NTSYS-pc (Rohlf, 1990, State University
New York, Stony Brook). A representative isolate from other formae speciales of $F$. oxysporum (lycopersici from tomato, conglutinans from cabbage, niveum from watermelon, melonis from cantaloupe, and capsici from pepper), and $F$. solani from sweetpotato were included in RAPD analyses as outgroups.

VCG. Vegetative compatibility was determined by Puhalla's modification (23) of Cove's (12) method of complementation

Table 1. Vegetative compatibility grouping (VCG), origin, and wilt indices on sweetpotato and tobacco for isolates of Fusarium oxysporum

\begin{tabular}{|c|c|c|c|c|c|c|c|}
\hline \multirow[b]{2}{*}{ Isolate } & \multirow[b]{2}{*}{ Host of origin } & \multirow{2}{*}{$\begin{array}{c}\text { Geographic } \\
\text { origin }\end{array}$} & \multicolumn{2}{|c|}{ Sweetpotato $^{\text {a }}$} & \multicolumn{2}{|c|}{ Tobacco $^{\text {b }}$} & \multirow[b]{2}{*}{$\mathrm{VCG}^{\mathrm{e}}$} \\
\hline & & & Porto Rico & Beauregard & Kentucky $5^{c}$ & Gold Dollard & \\
\hline \multicolumn{8}{|c|}{ RAPD cluster $I^{\mathrm{f}}$} \\
\hline FON-1g & Broadleaf tobacco & Connecticut & $2.04 \pm 0.50^{\mathrm{h}}$ & $0.27 \pm 0.43$ & $3.72 \pm 0.98$ & $1.11 \pm 0.62$ & $\ldots$ \\
\hline FON-3g & Broadleaf tobacco & Connecticut & $1.47 \pm 1.28$ & $0.30 \pm 0.73$ & $3.67 \pm 1.78$ & $0.67 \pm 0.63$ & $\ldots$ \\
\hline FON-9g & Broadleaf tobacco & Connecticut & $1.40 \pm 1.19$ & $0.00 \pm 0.00$ & $2.00 \pm 1.46$ & $0.27 \pm 0.44$ & $\ldots$ \\
\hline $10913^{\mathrm{i}}$ & Tobacco & Maryland & $1.33 \pm 0.86$ & $0.63 \pm 1.09$ & $3.88 \pm 1.02$ & $1.33 \pm 0.79$ & 8 \\
\hline FON-6g & Shade tobacco & Connecticut & $0.10 \pm 0.11$ & $0.00 \pm 0.00$ & $0.56 \pm 0.54$ & $0.00 \pm 0.00$ & $\ldots$ \\
\hline $84-45^{j}$ & Sweetpotato & South Carolina & $4.93 \pm 0.10$ & $1.71 \pm 2.23$ & $2.77 \pm 1.29$ & $1.11 \pm 1.49$ & SI \\
\hline $84-47^{j}$ & Sweetpotato & Georgia & $2.93 \pm 1.34$ & $0.23 \pm 0.37$ & $1.05 \pm 1.03$ & $0.05 \pm 0.11$ & 11 \\
\hline $85-26^{\mathrm{k}}$ & Sweetpotato & North Carolina & $0.97 \pm 0.61$ & $0.13 \pm 0.33$ & $0.95 \pm 0.93$ & $0.39 \pm 0.68$ & SI \\
\hline $85-28^{k}$ & Sweetpotato & North Carolina & $0.87 \pm 0.64$ & $0.00 \pm 0.00$ & $1.01 \pm 1.13$ & $0.60 \pm 0.55$ & SI \\
\hline FON-7g & Broadleaf tobacco & Connecticut & $0.12 \pm 0.17$ & $0.00 \pm 0.00$ & $2.02 \pm 1.19$ & $0.72 \pm 0.77$ & $\ldots$ \\
\hline FON-2g & Broadleaf tobacco & Connecticut & $0.80 \pm 0.68$ & $0.13 \pm 0.24$ & $2.08 \pm 1.76$ & $0.79 \pm 1.00$ & $3 ?$ \\
\hline Ft $-5^{1}$ & Flue-cured tobacco & North Carolina & $2.04 \pm 0.90$ & $1.00 \pm 0.89$ & $2.84 \pm 1.20$ & $1.27 \pm 1.02$ & 9 \\
\hline HDS95-2 $2^{1}$ & Flue-cured tobacco & North Carolina & $3.12 \pm 1.84$ & $1.83 \pm 2.01$ & $1.93 \pm 1.59$ & $0.69 \pm 0.60$ & 3 \\
\hline Ft-Stead ${ }^{\mathrm{l}}$ & Flue-cured tobacco & North Carolina & $1.72 \pm 1.29$ & $0.13 \pm 0.33$ & $2.33 \pm 1.19$ & $0.83 \pm 0.62$ & SI \\
\hline Ft-Rob ${ }^{1}$ & Flue-cured tobacco & North Carolina & $2.39 \pm 1.57$ & $1.09 \pm 1.12$ & $3.56 \pm 1.22$ & $1.78 \pm 1.31$ & 3 \\
\hline Ft-92 & Flue-cured tobacco & North Carolina & $1.14 \pm 0.99$ & $0.67 \pm 1.21$ & $1.97 \pm 1.59$ & $1.49 \pm 0.97$ & 3 \\
\hline \multicolumn{8}{|c|}{ RAPD cluster II, subgroup A } \\
\hline $92-11^{\mathrm{m}}$ & Sweetpotato & California & $3.79 \pm 1.26$ & $2.53 \pm 2.17$ & $0.06 \pm 0.13$ & $0.00 \pm 0.00$ & 2 \\
\hline $93-02^{\mathrm{m}}$ & Sweetpotato & California & $3.95 \pm 1.09$ & $2.32 \pm 2.01$ & $0.06 \pm 0.13$ & $0.00 \pm 0.00$ & 2 \\
\hline $93-01^{\mathrm{m}}$ & Sweetpotato & California & $3.36 \pm 1.25$ & $2.38 \pm 2.22$ & $0.22 \pm 0.40$ & $0.00 \pm 0.00$ & 2 \\
\hline CB-3 & Sweetpotato & California & $2.36 \pm 1.47$ & $1.18 \pm 1.40$ & $0.42 \pm 0.57$ & $0.05 \pm 0.11$ & 2 \\
\hline \multicolumn{8}{|c|}{ RAPD cluster II, subgroup B } \\
\hline CB-4 & Sweetpotato & California & $0.47 \pm 0.81$ & $0.44 \pm 0.51$ & $0.00 \pm 0.00$ & $0.00 \pm 0.00$ & 6 \\
\hline CB-5 & Sweetpotato & California & $0.00 \pm 0.00$ & $0.43 \pm 0.79$ & $0.00 \pm 0.00$ & $0.00 \pm 0.00$ & 7 \\
\hline \multicolumn{8}{|c|}{ RAPD cluster III } \\
\hline $16415^{\mathrm{n}}$ & Sweetpotato? & South Carolina & $3.97 \pm 1.22$ & $0.46 \pm 0.57$ & $0.47 \pm 0.62$ & $0.00 \pm 0.00$ & 5 \\
\hline WJM-7º & Sweetpotato & Louisiana & $4.21 \pm 0.82$ & $1.15 \pm 1.48$ & $0.39 \pm 0.68$ & $0.00 \pm 0.00$ & SI \\
\hline \multicolumn{8}{|c|}{ RAPD cluster IV } \\
\hline $79-4$ & Sweetpotato & Louisiana & $4.43 \pm 0.84$ & $1.23 \pm 1.29$ & $0.50 \pm 0.59$ & $0.00 \pm 0.00$ & 1 \\
\hline $79-5$ & Sweetpotato & Louisiana & $1.27 \pm 1.22$ & $0.43 \pm 0.79$ & $0.06 \pm 0.13$ & $0.11 \pm 0.17$ & 1 \\
\hline $84-48^{j}$ & Sweetpotato & Louisiana & $2.90 \pm 0.83$ & $0.20 \pm 0.25$ & $0.33 \pm 0.42$ & $0.06 \pm 0.13$ & SI \\
\hline $85-8$ & Sweetpotato & Louisiana & $3.00 \pm 2.21$ & $0.54 \pm 0.93$ & $0.50 \pm 0.75$ & $0.00 \pm 0.00$ & 1 \\
\hline \multicolumn{8}{|c|}{ RAPD cluster V } \\
\hline $84-46^{j}$ & Sweetpotato & North Carolina & $4.21 \pm 0.93$ & $2.02 \pm 2.22$ & $0.89 \pm 0.58$ & $0.06 \pm 0.13$ & SI \\
\hline $85-27^{\mathrm{k}}$ & Sweetpotato & North Carolina & $3.40 \pm 1.28$ & $0.63 \pm 0.95$ & $0.42 \pm 0.49$ & $0.05 \pm 0.11$ & SI \\
\hline \multicolumn{8}{|l|}{ Not clustered } \\
\hline $78-45$ & Sweetpotato & Louisiana & $0.00 \pm 0.00$ & $0.00 \pm 0.00$ & $0.00 \pm 0.00$ & $0.00 \pm 0.00$ & 4 \\
\hline FON-5 & Broadleaf tobacco & Connecticut & $0.00 \pm 0.00$ & $0.00 \pm 0.00$ & $0.16 \pm 0.41$ & $0.17 \pm 0.41$ & $\ldots$ \\
\hline FON-10g & Tobacco & Greece & $0.00 \pm 0.00$ & $0.00 \pm 0.00$ & $0.00 \pm 0.00$ & $0.00 \pm 0.00$ & $\ldots$ \\
\hline Ft-Samp ${ }^{1}$ & Flue-cured tobacco & North Carolina & $0.00 \pm 0.00$ & $0.00 \pm 0.00$ & $0.06 \pm 0.13$ & $0.00 \pm 0.00$ & 10 \\
\hline Ft-1512 & Flue-cured tobacco & North Carolina & $2.92 \pm 0.77$ & $0.47 \pm 1.04$ & $1.94 \pm 1.16$ & $0.33 \pm 0.37$ & SI \\
\hline Holc $1.1^{p}$ & Okra & Louisiana & $0.00 \pm 0.00$ & $0.00 \pm 0.00$ & $1.73 \pm 0.88$ & $0.15 \pm 0.22$ & 11 \\
\hline TAM-3p & Cotton & Texas & $0.03 \pm 0.08$ & $0.00 \pm 0.00$ & $2.36 \pm 1.85$ & $0.59 \pm 0.61$ & 12 \\
\hline
\end{tabular}

a Porto Rico = susceptible, Beauregard = resistant.

${ }^{\mathrm{b}}$ Kentucky $5=$ burley, Gold Dollar $=$ flue-cured.

${ }^{\mathrm{c}}$ Least significant difference (LSD) $(\alpha=0.05)=1.13, F=8.59, \operatorname{Pr}>F=0.0001$.

${ }^{\mathrm{d}} \operatorname{LSD}(\alpha=0.05)=0.62, F=4.36, \operatorname{Pr}>F=0.0001$.

e $\mathrm{SI}=$ self-incompatible.

${ }^{\mathrm{f}} \mathrm{RAPD}=$ random amplified polymorphic DNA.

g Obtained from J. La Mondia, Connecticut Agricultural Experiment Station, Windsor, 1996.

${ }^{\text {h }}$ Wilt index (from $0=$ no symptoms to $5=$ plant dead) \pm standard deviation.

i American Type Culture Collection (ATCC) \# - originally from W. F. Jeffers.

j Obtained from P. D. Dukes, United States Department of Agriculture Vegetable Lab, Charleston, SC, 1984.

${ }^{k}$ Obtained from J. W. Moyer, North Carolina State Univ., Raleigh, 1985.

${ }^{1}$ Obtained from H. D. Shew, North Carolina State Univ., Raleigh, 1996.

${ }^{\mathrm{m}}$ Obtained from Bob Campbell, University of California, Davis, 1994.

${ }^{\mathrm{n}}$ ATCC \# - originally from G. M. Armstrong.

o Obtained from W. J. Martin, Louisiana Agricultural Experiment Station, Baton Rouge, 1977.

${ }^{\mathrm{p}}$ Obtained from L. L. Black, Louisiana Agricultural Experiment Station, Baton Rouge. 
tests between nitrate nonutilizing mutants (nits). Mycelia were transferred from PDA to potato sucrose agar (KPS) or minimal salts medium (MM) plus $1.6 \mathrm{~g} /$ liter L-asparagine (KMM), each supplemented with $1.5 \% \mathrm{KClO}_{3}$. Some isolates had a uniform, rapid growth on media containing $1.5 \%$ $\mathrm{KClO}_{3}$ and these were grown on the same media supplemented with 3.0 or $4.5 \%$ $\mathrm{KClO}_{3}$. Transfers were made from the leading margin of any fast-growing sectors that appeared on KPS or KMM to MM. Cultures with a thin, expansive growth on MM were considered nits and their phenotypes were determined by the method of Correll et al. $(10,11)$. They were grown on MM containing either nitrate, nitrite, hypoxanthine, ammonium, or uric acid as a nitrogen source. Nits were transferred to the phenotype media in the "daisy" configuration described by Puhalla (23), with one mutant in the center of the plate and several mutants in a circle around it. In addition to recording phenotype, any complementation that occurred between nits was recorded. At least 1 nit $\mathrm{M}$ and 1 nit 1 or nit 3 were obtained for each isolate.

To test for complementation or heterokaryon formation between nits, mycelia were transferred from PDA to MM with a nitM in the center of a daisy configuration and several nit $1 \mathrm{~s}$ or nit 3 s around the outer circle. The plates were incubated in darkness at $28^{\circ} \mathrm{C}$ for up to 14 days. If a continuous line of robust aerial mycelia developed within 5 to 10 days where the thin expansive growth of the nits converged, heterokaryon formation was considered to have occurred and the complementary nits were placed in the same VCG. For each isolate, a representative nitM, nit 1 , or nit 3 was paired with representative nits for all the other isolates. To avoid the possibility that interference among some nits might inhibit heterokaryon formation between other nits, pairings that did not form heterokaryons were repeated by transferring blocks of PDA from cultures of the 2 nits to 6-cm-diameter petri dishes with MM. For several isolates, robust mycelia did not form between pairings of the original nitM and nit 1 or nit3. Additional nitMs were collected from such isolates and paired with all available nit $1 \mathrm{~s}$ and nit $3 \mathrm{~s}$ for the same isolate. If none of the combinations produced robust mycelia, the isolate was considered to be heterokaryon self-incompatible (20). The Connecticut tobacco isolates were originally provided as nits but had apparently lost the ability to form heterokaryons, as they did not produce robust mycelia in any combination. Therefore, there were not included in VCG analysis. All pairings were repeated.

\section{RESULTS}

Pathogenicity. Isolates varied in pathogenicity and severity of symptoms produced in cultivars of sweetpotato and tobacco (Table 1). Generally, wilt indices were lower on Gold Dollar (flue-cured) than Kentucky 5 (burley) tobacco. With the exception of one nonpathogenic isolate (FON-5) and isolate FON-6, which caused relatively mild symptoms, the isolates from broadleaf/shade tobacco from Connecticut were lethal to Kentucky 5 and caused moderate to severe wilting in Gold Dollar but caused little or no disease on both cultivars of sweetpotato. Isolates from North Carolina flue-cured tobacco caused severe wilt in the susceptible sweetpotato cultivar Porto Rico, were generally lethal to Kentucky 5, and caused mild to moderate wilting on the resistant sweetpotato cultivar Beauregard and Gold Dollar. The California sweetpotato isolates caused severe wilting of Porto Rico, low to moderate levels of wilt on Beauregard, and did not cause disease on the tobacco cultivars. Several southeastern sweetpotato isolates caused lethal wilting of Porto Rico, very mild wilting of Kentucky 5, but were nonpathogenic on Beauregard or Gold Dollar. Other southeastern sweetpotato isolates caused severe wilting on Porto Rico and both tobaccos but were nonpathogenic on Beauregard. Isolates TAM-3 and Holc 1.1 of $F$. oxysporum f. sp. vasinfectum from cotton and okra, respectively, caused moderate to severe wilt on cotton and Kentucky 5 , but none of the other isolates induced symptoms on cotton (data not shown).

When CB-3, a California sweetpotato isolate, and WJM-7, a southeastern sweetpotato isolate, were compared in inoculum density tests, results varied from test to test. This was especially true for results with CB-3, which in nine tests induced levels of disease varying from mild wilt on both Porto Rico and Beauregard to severe but not lethal wilt on both cultivars. In four tests, WJM-7 consistently killed most Porto Rico plants and caused mild or no symptoms on Beauregard. Generally, the difference in reaction between the two cultivars was not as great with CB-3 as for WJM-7 (Table 1). CB-3 induced less severe wilting on Porto Rico than WJM-7, but more severe wilting of Beauregard. Results from two of the inoculum density tests did not differ significantly $(\operatorname{Pr}>F=$ $0.97)$ and were combined (Fig. 1). $R^{2}$ was $0.71(P r>F=0.0001), 0.55(P r=0.0001)$, $0.09(P r=0.037)$, and $0.24(P r=0.0004)$ for Porto Rico inoculated with WJM-7 and CB-3, and Beauregard inoculated with WJM-7 and CB-3, respectively.

RAPD analysis. Of the 20 primers in Operon kit A that were used, 17 led to amplification of PCR products, including at least one polymorphic product. The size of amplified DNA fragments generated with the 17 primers ranged from about 0.2 to $3.5 \mathrm{~kb}$. The number of polymorphic fragments produced with each primer was 1 to 12 in each isolate. The similarity coefficients among isolates ranged from 0.10 to 1.00 , where 1.00 is identical. All 17 primers revealed polymorphisms useful for classifying isolates, and Figure 2 shows amplifications with primers OPA-2, 4, and 5. Cluster analysis using a cutoff of similarity $\geq 0.90$ revealed five genetically distinct clusters, designated I to $\mathrm{V}$, among the isolates (Fig. 3). Cluster I contained all isolates from tobacco except FON-5 and FON-10. It also included one isolate each from South Carolina and Georgia and two from North Carolina that were originally isolated from sweetpotato. Cluster II consisted of all sweetpotato isolates from California, cluster III consisted of sweetpotato isolates ATCC-16415 and WJM-7, cluster IV included four sweetpotato isolates from Louisiana, and cluster $\mathrm{V}$ included two sweetpotato isolates from North Carolina. Isolates 78-45 from sweetpotato, FON-5 and FON-10 from tobacco, and the individual representative isolates from other formae speciales of $F$. oxysporum (lycopersici from tomato, conglutinans from cabbage, niveum from watermelon, melonis from cantaloupe, and capsici from pepper), and $F$. solani from sweetpotato were not clustered.

Vegetative compatibility. Of the 29 isolates included in VCG analysis, nine were heterokaryon self-incompatible. An additional eight isolates formed singlemember VCGs. Only three multiple-member VCGs were identified. VCG 1 included three sweetpotato isolates from Louisiana, VCG 2 included all four pathogenic California sweetpotato isolates, and VCG 3 included three tobacco isolates from North Carolina. In each case, all members of a multiple-member VCG also fell within the same cluster defined by RAPDs.

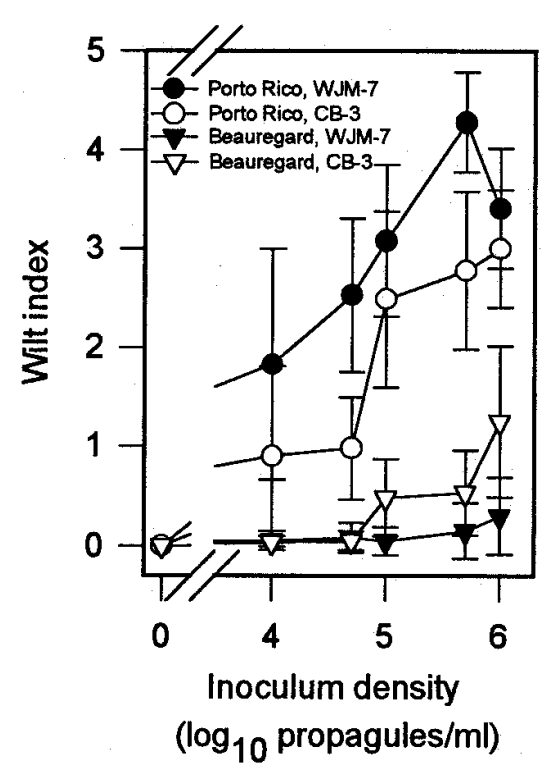

Fig. 1. Relationship between inoculum density and Fusarium wilt severity on the wilt-susceptible sweetpotato cultivar Porto Rico and the wilt-resistant cultivar Beauregard following inoculation with isolate CB-3, originally isolated from Beauregard in California, and isolate WJM-7, originally isolated from sweetpotato in Louisiana. Error bars represent standard deviations. 


\section{DISCUSSION}

Cluster analysis of similarity coefficients based on RAPD profiles revealed discrete clusters of isolates, possibly representing different lineages, among wiltinducing isolates of $F$. oxysporum from sweetpotato and tobacco. These clusters

\section{M $12234556789910111213 M$}
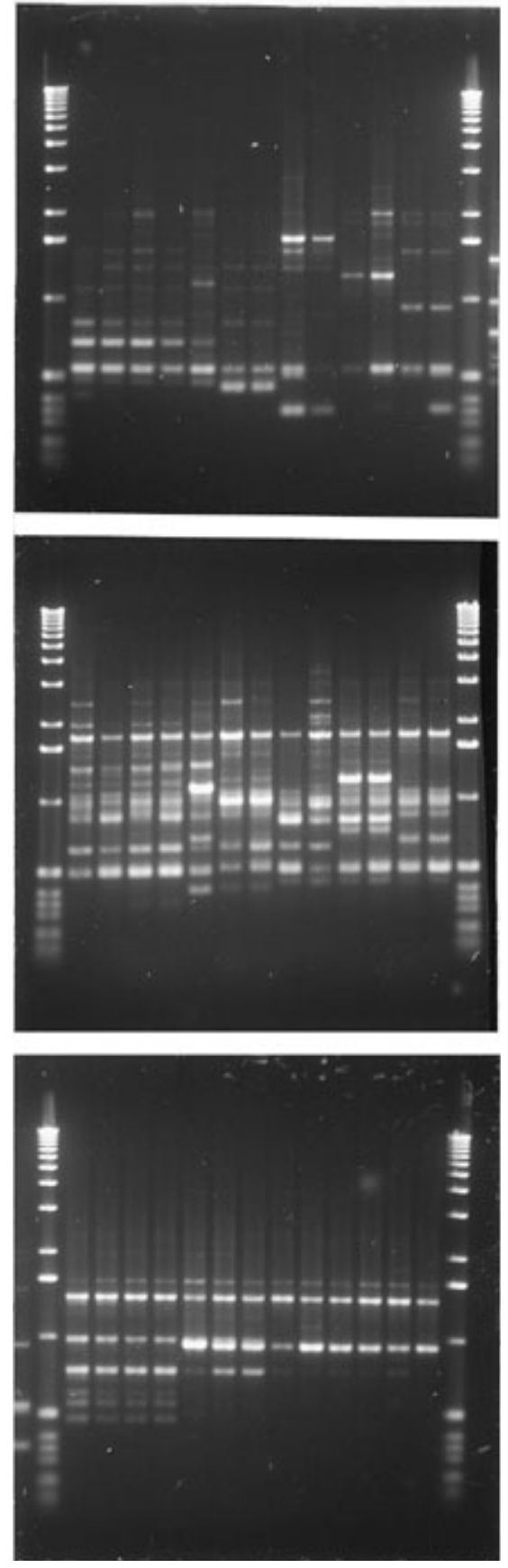

Fig. 2. Electrophoresis gels (1.5\% agarose) showing amplification products from randomly primed polymerase chain reaction using template DNA from different isolates of Fusarium oxysporum from sweet potato and tobacco. Top $=$ primer $\mathrm{OPA}-5$, middle $=$ primer $\mathrm{OPA}-2$, and bottom $=$ primer OPA-4. $\mathrm{M}=$ marker DNA $(1$ kilobase ladder). Lane $1=$ isolate FON-1, $2=$ ATCC-10913, $3=84-45,4=85-26,5=$ FtStead, $6=92-11,7=$ CB-3, $8=$ ATCC-16415, $9=$ WJM-7, $10=79-4,11=84-48,12=84-46$, and $13=85-27$. corresponded to differences in pathogenicity characteristics and were distinguished from isolates representing formae speciales of $F$. oxysporum from hosts other than sweetpotato and tobacco. VCG was less useful in assessing relationships among these isolates because a large proportion of the isolates were self-incompatible and incompatible with all other isolates. Such isolates may have lost the ability to form heterokaryons after extended culturing. For those isolates that did form multiple-member VCGs, all members of a VCG were included within a single RAPD cluster. Thus, there was agreement among results from the different methods used to compare and relate the isolates to one another.

Although some of the isolates used in this study were isolated many years ago, they have been stored on silica gel and most remain pathogenic on their host of origin. However, a few (FON-6, 85-26, 8528, and 84-47) may have diminished aggressiveness. It is possible that isolates 7845, FON-5, FON-10, and Ft-Samp, which did not cause wilt in any of the hosts tested, may have been nonpathogenic strains originally. Our results for isolates ATCC-10913 from tobacco and ATCC16415 from sweetpotato differ from those of La Mondia (19). He placed both isolates in the same VCG, while we found our cultures, which were obtained independently, to be vegetatively incompatible, which is consistent with the differences in RAPD profiles and pathogenicity observed in this study.

None of the sweetpotato or tobacco isolates induced symptoms in cotton, and since they also differed from TAM-3 and Holc 1.1 in RAPD profiles, we consider them to be distinct from $F$. oxysporum $\mathrm{f}$. sp. vasinfectum. All isolates that caused lethal wilting of Kentucky 5 burley tobacco and moderate to severe wilting of Gold Dollar flue-cured tobacco were grouped in RAPD cluster I, except for one tobacco isolate and the two isolates of $F$. oxysporum f. sp. vasinfectum that were not clustered with any isolates. Cluster I included 12 isolates originally obtained from tobacco and four isolates from sweetpotato from states where tobacco and sweetpotato are commonly grown in rotation. One of these, isolate 84-45, also was highly aggressive on Porto Rico sweetpotato.

The majority of southeastern sweetpotato isolates fell into three small related clusters, two of which corresponded to geographic origin of the isolates. These isolates did not cause symptoms on Gold Dollar and only mild symptoms, primarily vascular discoloration without wilting, on Kentucky 5 burley tobacco. They varied from weakly to highly aggressive on Porto Rico but caused only mild symptoms on Beauregard. Unfortunately, it is not feasible to obtain additional isolates from sweetpotato in the southeastern United States, because the disease has diminished to nondetectable levels since the widespread adoption of resistant cultivars. This precludes a thorough analysis of genetic diversity and structure within this forma specialis. However, these isolates appear more diverse by RAPD analysis than the tobacco or California sweetpotato isolates.

Armstrong and Armstrong (1) and McClure (22) inoculated tobacco after root wounding while Smith and Shaw (26) used a transplant dip inoculation protocol similar to that used in this study. Each of the earlier workers also presented results as quantal responses (per cent plants with external symptoms or per cent plants infected) rather than including quantitative assessments of disease severity. Hendrix and Nielsen (17) demonstrated that several different formae speciales of $F$. oxysporum can induce vascular browning in sweetpotato, even though they induce no external symptoms and, conversely, $F$. oxysporum $\mathrm{f}$. sp. batatas can cause vascular discoloration in several crops that do not develop wilt. Thus, it is important to compare severity of symptoms produced as well as qualitative responses. The differences in inoculation methods and disease evaluations in earlier studies may have obscured the differences in pathogenicity characteristics on tobacco reported here. We found the cluster I isolates to be distinctly more aggressive on both cultivars of tobacco than the other isolates, which generally caused only vascular discoloration or mild wilting. The severity of wilt induced by the cluster I isolates was more variable in sweetpotato than in tobacco.

The differences in host-pathogen interactions observed in this study, coupled with the fact that the isolates formed distinct clusters in RAPD and VCG analyses, indicate at least three genetically distinct evolutionary lineages that correspond to pathogenicity characteristics among the isolates. Genetically distinct lineages have been found within $F$. oxysporum f. sp. cubense (4) and even within a single race (race 3) of F. oxysporum f. sp. lycopersici (21). On the other hand, RAPDs have been used to distinguish different races of $F$. solani f. sp. cucurbitae (13). For F. solani, it was possible to correlate RAPD clusters with mating population, which is not possible with the asexual $F$. oxysporum. Thus, it is not clear at what level the genetic distinctions implied with RAPDs should be used to separate forma specialis, race, or other taxonomic subgroups within $F$. $o x$ ysporum.

The isolates from RAPD clusters IIA, III, IV, and V appear to share pathogenic specialization to sweetpotato. On both burley and flue-cured tobacco, they primarily caused vascular discoloration without external symptoms of wilting, which several formae speciales are known to cause in heterologous hosts (17). In preliminary host range tests, isolates 84-45 (cluster I), CB-3 (cluster IIA), and WJM-7 
(cluster III) did not cause wilt on cabbage (Early Jersey Wakefield), cantaloupe (Topmark), cotton (Stoneville 825), tomato (Bonny Best), or watermelon (Sugar Baby; Clark, unpublished data), while isolates of homologous formae speciales for each host caused severe wilting. Thus, we propose that the isolates from clusters IIA, III, IV, and $\mathrm{V}$ all be included in $F$. oxysporum $\mathrm{f}$. sp. batatas. Since they did not cause wilting in Kentucky 5 burley tobacco, they differ from the descriptions of both races of $F$. oxysporum f. sp. batatas proposed by earlier workers $(1,26)$.

The isolates from clusters III, IV, and V were differentially virulent on the susceptible Porto Rico and resistant Beauregard, and although arbitrarily assigned to different clusters, had similarity coefficients between clusters of $>0.70$. Cluster IIA included four isolates from two different sources that formed one vegetative compatibility group, had $>0.95$ similarity coefficients, and all caused moderate to severe wilting of Porto Rico and mild to moderate wilting of Beauregard. We therefore propose that isolates from clusters III, IV, and $\mathrm{V}$ represent the original race 0 , and the isolates from cluster IIA represent a new race, race 1 of $F$. oxysporum f. sp. batatas. Since they are in the same VCG, very similar in RAPD profile, and from the same host and geographic origin, the cluster IIA isolates are probably clonally related. The two isolates in cluster IIB were nonpathogenic on both cultivars of tobacco and sweetpotato and may have diverged from the pathogenic subgroup concomitant with loss of pathogenicity.

Nomenclature for the isolates from cluster I is not as easily defined, since most are pathogenic on at least two host species from different families (tobacco $=$ Solana ceae, sweetpotato = Convolvulaceae . Armstrong and Armstrong (3) rejected $F$. oxysporum f. sp. nicotianae because they could find no record of isolates specific to tobacco, placing isolates from tobacco in $F$. oxysporum f. sp. batatas even though they were not specific to sweetpotato. Since, with significant exceptions, cluster I isolates are generally less virulent on sweetpotato than the isolates from $F$. oxysporum f. sp. batatas as defined above, and since most were originally isolated from tobacco and caused severe wilting on tobacco, we favor designating them as $F$. oxysporum $\mathrm{f}$. sp. nicotianae. However, although they are generally more aggressive on tobacco than sweetpotato, some isolates were highly aggressive on sweetpotato. Furthermore, since four of these isolates were originally isolated from sweetpotato, it appears that they can infect sweetpotato under field conditions. That the cluster I isolates varied in ability to cause wilt in burley tobacco and sweetpotato would suggest that this cluster contains isolates corresponding to descriptions of both of the races of $F$. oxysporum f. sp. batatas proposed earlier $(1,26)$. The overlapping host ranges of formae speciales $F$. oxysporum f. sp. batatas, $F$. oxysporum f. sp. nicotianae, and $F$. oxysporum f. sp. vasinfectum were recognized originally because these crops were

\section{Similarity}
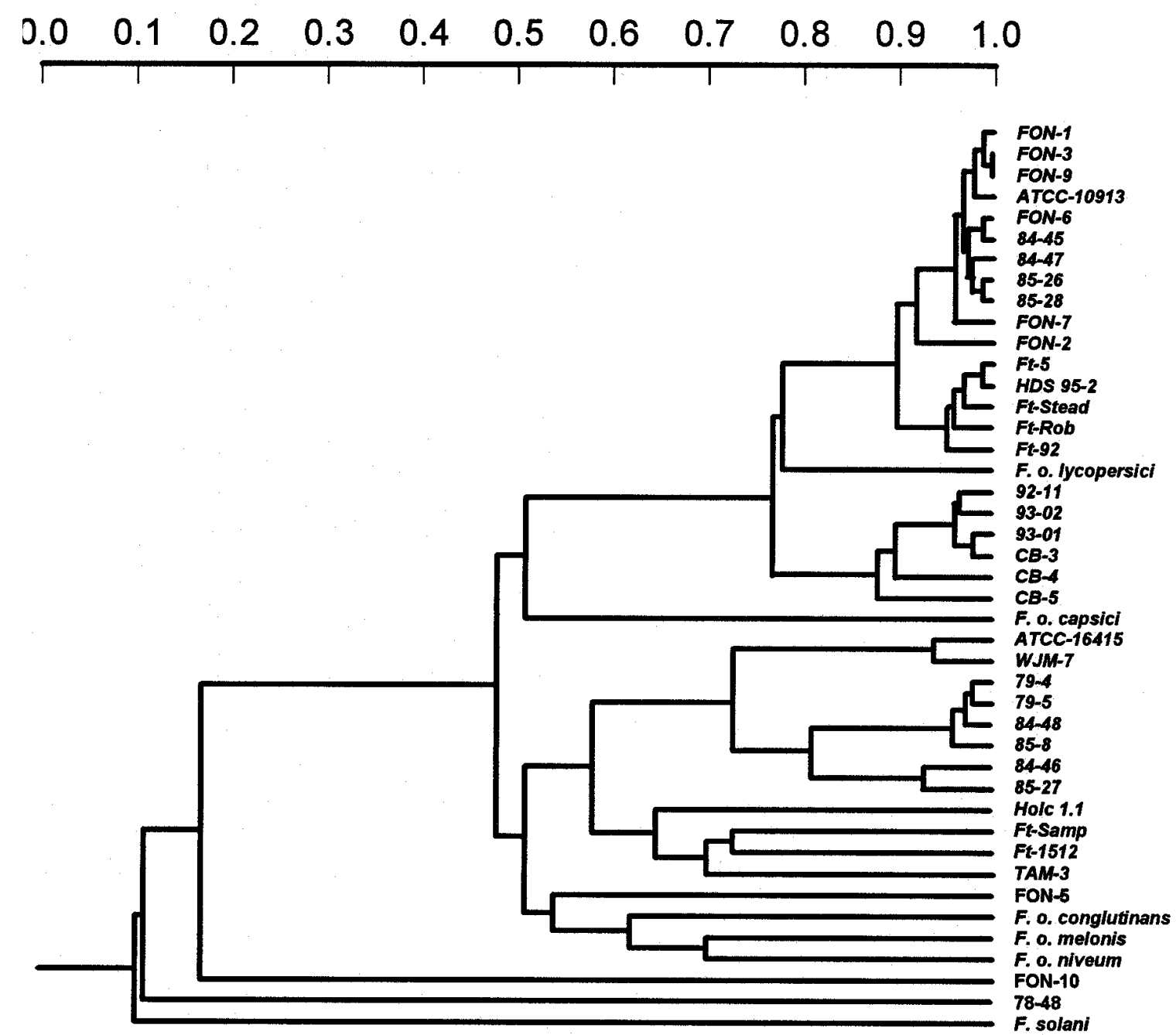

Fig. 3. Dendrogram showing similarities among isolates of Fusarium oxysporum as determined by cluster analysis of random amplified polymorphic DNA data using 17 primers. 
commonly grown in rotation and because earlier workers did exhaustive cross-inoculations of plants from different families $(1,2,17,26)$. Less extensive inoculations have been done for many other formae speciales of $F$. oxysporum. If a sufficiently wide array of plants could be inoculated, it might be found that some of these formae speciales also cause wilt on hosts other than the specific host on which they are currently recognized.

Although race 1 of $F$. oxysporum $\mathrm{f}$. sp. batatas caused wilt on the resistant cultivar Beauregard, in this study it generally was less aggressive than are race 0 isolates on the susceptible Porto Rico. Wilt indices also were more variable among tests for race 1 isolates, which may be due to variations in succulence of the plants among tests. This variation might have a greater affect on isolates that are only moderately aggressive than on highly aggressive isolates. Fusarium wilt has not been reported to occur on resistant cultivars, including Beauregard, in the southeastern United States as it has in California. Thus, it appears that race 1 by itself may not pose a serious threat to sweetpotato production, especially since it has not been found in the southeastern United States where most sweetpotato production occurs. However, since E. chrysanthemi also was isolated from the same plants, the possibility that these two pathogens may interact to cause economic losses, as has previously been reported on sweetpotato for $F$. solani and E. chrysanthemi (14), should be explored.

Isolates from race 0 have been used predominantly in the United States for screening sweetpotato breeding clones for resistance. As expected, these isolates induced strongly differential reactions in the susceptible cultivar Porto Rico and the resistant Beauregard. Since these isolates appear to be highly aggressive on sweetpotato, and since use of resistant cultivars generated as a result of screening with these isolates appears to have remained effective in the major sweetpotato-growing areas, race 0 isolates will likely remain the primary isolates used in future screening efforts. However, it is interesting that the race 1 isolates and the isolates of $F$. oxysporum f. sp. nicotianae, although they are generally less aggressive on sweetpotato, did not elicit a distinctly differential reaction on Porto Rico and Beauregard. It may be that these isolates interact differently with the host (9). Thus, it would be of value to determine if sweetpotato germplasm is available that is more highly resistant than Beauregard, especially to race 1. It also would be of interest to determine if continued cycles of inoculation and reisolation of these isolates in Beauregard or other resistant genotypes can lead to selection for greater aggressiveness on the resistant cultivars.

\section{ACKNOWLEDGMENTS}

We thank L. L. Black, formerly of the Louisiana Agricultural Experiment Station; R. N. Campbell, University of California at Davis; P. D. Dukes, United States Department of Agriculture, Charleston; J. La Mondia, Connecticut Agricultural Experiment Station; W. J. Martin, Louisiana Agricultural Experiment Station, deceased; and J. W. Moyer and H. D. Shew, North Carolina State University, for providing cultures.

\section{LITERATURE CITED}

1. Armstrong, G. M., and Armstrong, J. K. 1958. The Fusarium wilt complex as related to the sweetpotato. Plant Dis. Rep. 42:1319-1329.

2. Armstrong, G. M., and Armstrong, J. K. 1959. Physalis alkekengi $\mathrm{L}$. a new host for the U. S. cottoncassia, and sweetpotato-wilt Fusaria. Plant Dis. Rep. 43:509-510.

3. Armstrong, G. M., and Armstrong, J. K. 1968. Formae speciales and races of Fusarium oxysporum causing a tracheomycosis in the syndrome of disease. Phytopathology 58:12421246.

4. Bentley, S., Pegg, K. G., and Dale, J. L. 1995. Genetic variation among a world-wide collection of isolates of Fusarium oxysporum $\mathrm{f}$. sp. cubense analyzed by RAPD-PCR fingerprinting. Mycol. Res. 99:1378-1384.

5. Bonsi, C. K., Bouwkamp, J. C., Hill, W. A., and Loretan, P. A. 1992. Production practices. Pages 29-43 in: Fifty Years of Cooperative Sweetpotato Research, 1939-1989. A. Jones and J. C. Bouwkamp, eds. South. Coop. Ser. Bull. No. 369.

6. Clark, C. A. 1994. The chlorotic leaf distortion pathogen, Fusarium lateritium, cross protects sweetpotato against Fusarium wilt caused by Fusarium oxysporum f. sp. batatas. Biol. Control 4:59-66.

7. Clark, C. A., Dukes, P. D., and Moyer, J. W. 1992. Diseases. Pages 88-105 in: Fifty Years of Cooperative Sweetpotato Research, 19391989. A. Jones and J. C. Bouwkamp, eds. South. Coop. Ser. Bull. No. 369.

8. Clark, C. A., and Moyer, J. W. 1988. Compendium of Sweet Potato Diseases. American Phytopathological Society Press, St. Paul, MN.

9. Correll, J. C. 1991. The relationship between formae speciales, races, and vegetative compatibility groups in Fusarium oxysporum. Phytopathology 81:1061-1064.

10. Correll, J. C., Klittich, C. J. R., and Leslie, J. F. 1987. Nitrate nonutilizing mutants of Fusarium oxysporum and their use in vegetative compatibility tests. Phytopathology 77:1640-1646.

11. Correll, J. C., Klittich, C. J. R., and Leslie, J.
F. 1989. Heterokaryon self-incompatibility in Gibberella fujikuroi (Fusarium moniliforme). Mycol. Res. 93:21-27.

12. Cove, D. J. 1976. Chlorate toxicity in Aspergillus nidulans: The selection and characterization of chlorate resistant mutants. Heredity 36:191-203.

13. Crowhurst, R. N., Hawthorne, B. T., Rikkerink, E. H. A., and Templeton, M. D. 1991. Differentiation of Fusarium solani f. sp. $\mathrm{cu}$ curbitae races 1 and 2 by random amplification of polymorphic DNA. Curr. Genet 20:391-396.

14. Duarte V., and Clark, C. A. 1993. Interaction of Erwinia chrysanthemi and Fusarium solani on sweetpotato. Plant Dis. 77:733-735.

15. Dukes, P. D., Bohac, J. R., and Mueller, J. D. 1993. Disease reactions of regional and advanced breeding lines, selected and standard cultivars of sweetpotato to stem rot, 1992 Biol. Cult. Tests 8:33.

16. Dukes, P. D., Bohac, J. R., and Mueller, J. D. 1994. Disease reactions of regional breeding lines, standard and selected cultivars of sweetpotato to stem rot (wilt), 1993. Biol Cult. Tests 9:51.

17. Hendrix, F. F., Jr., and Nielsen, L. W. 1958. Invasion and infection of crops other than the forma suscept by Fusarium oxysporum f. batatas and other formae. Phytopathology 48:224-228.

18. Johnson, J. 1921. Fusarium-wilt of tobacco. J. Agric. Res. 20:515-535.

19. La Mondia, J. A. 1990. Pathogenicity and vegetative compatibility of Fusarium oxysporum isolated from tobacco. Tob. Int. (NY) 192(22):58-61.

20. Leslie, J. F. 1993. Fungal vegetative compatibility. Annu. Rev. Phytopathol. 31:127-151.

21. Marlatt, M. L., Correll, J. C., Kaufmann, P., and Cooper, P. E. 1996. Two genetically distinct populations of Fusarium oxysporum $\mathrm{f}$. sp. lycopersici race 3 in the United States. Plant Dis. 80:1336-1342.

22. McClure, T. T. 1949. Mode of infection of the sweet-potato wilt Fusarium. Phytopathology 39:876-886.

23. Puhalla, J. E. 1985. Classification of strains of Fusarium oxysporum on the basis of vegetative compatibility. Can. J. Bot. 63:179-183.

24. Rolston, L. H., Clark, C. A., Cannon, J. M., Randle, W. M., Riley, E. G., Wilson, P. W., and Robbins, M. L. 1987. "Beauregard" sweetpotato. HortScience 22:1338-1339.

25. Shew, H. D., and Lucas, G. B., eds. 1991 Compendium of Tobacco Diseases. American Phytopathological Society Press, St. Paul, $\mathrm{MN}$.

26. Smith, T. E., and Shaw, K. J. 1943. Pathogenicity studies with Fusaria isolated from tobacco, sweet potato and cotton. Phytopathology 33:469-483.

27. Windels, C. E., Burnes, P. M., and Kommedahl, T. 1988. Five-year preservation of Fusarium species on silica gel and soil. Phytopathology 78:107-109.

28. Yoon, C. S. 1992. Molecular systematics and population genetics of Hypoxylon truncatum sensu Miller using RAPD. Ph.D. Dissertation, Illinois State Univ. 